www.jmscr.igmpublication.org

Index Copernicus Value: 79.54

ISSN (e)-2347-176x ISSN (p) 2455-0450

crossref DOI: https://dx.doi.org/10.18535/jmscr/v7i6.180

Journal Of Medical Science And Clinical Research

IGM Publication

An Official Publication of IGM Publication

\title{
A Prospective Observational Study of Role of Modified Alvarado Score, Ultrasound Abdomen and Histopathology in the Diagnosis of Acute Appendicitis
}

\author{
Authors \\ Dr Sirikonda Srikanth, Dr Thogari Kranthi Kumar*, Dr K.S. Lakshmi Sri Vidya \\ *Corresponding Author \\ Dr Thogari Kranthi Kumar
}

\begin{abstract}
Appendicitis is the one of the most common surgical emergency with a lifetime risk of $8.6 \%$ in males and $6.7 \%$ in females. The diagnosis of acute appendicitis is predominantly based on clinical findings. When appendicitis manifests in its classic form, it is easily diagnosed and treated. This study tries to correlate between clinically diagnosed acute appendicitis and histopathologically examined specimen. In view of the above, it was decided to study the correlation between the combination of modified Alvarado score (MAS) and ultrasound in reducing negative appendicectomy rates and to determine the accuracy between them.

In our study we found that Ultrasonography and Modified Alvarado Score are both beneficial in diagnosis of acute appendicitis.

Keywords: appendicitis, modified Alvarado score (MAS), appendicectomy.
\end{abstract}

\section{Introduction}

Appendicitis is the one of the most common surgical emergency with a lifetime risk of $8.6 \%$ in males and $6.7 \%$ in females. ${ }^{1}$ The diagnosis of acute appendicitis is predominantly based on clinical findings. When appendicitis manifests in its classic form, it is easily diagnosed and treated. Unfortunately, these classic symptoms occur in just over half of patients, therefore an accurate and timely diagnosis of atypical appendicitis remains clinically challenging and is one of the most commonly missed problems in the emergency department.

Furthermore, the consequence of missing appendicitis, leading to perforation, significantly increases morbidity and prolongs hospital stay. ${ }^{2}$ Although the mortality rate has been vastly reduced, the diagnostic inaccuracy rate of $15 \%$ to $20 \%$ has remained unchanged in the past century. High rates of negative appendicectomy (operation without histological confirmation of appendicitis) have been reported with some groups such as females of reproductive age (up to $26 \%$ ). ${ }^{3}$ The main factors contributing to this high negative laparotomy rate have been the nonspecific clinical features of acute appendicitis. A complication rate of up to $6.1 \%$ following removal of normal appendices was also reported ${ }^{4}$ 
To decide between lesser of two evils, that is, a negative appendicectomy or an appendicular perforation can be often be a vexing problem. Ultrasound has been proposed as an ideal noninvasive adjunct to diagnosis in suspected appendicitis.

This study tries to correlate between clinically diagnosed acute appendicitis and histopathologically examined specimen. In view of the above, it was decided to study the correlation between the combination of modified Alvarado score and ultrasound in reducing negative appendicectomy rates and to determine the accuracy between them.

\section{Materials and Methodology}

Source of data were patients of all age, either sex, admitted under the Department of General Surgery, Kamineni Hospitals with the diagnosis of acute appendicitis and undergoing appendicectomy.

Study period was from June 2015 to March 2017. It was a prospective observational study.

A total minimum number of 150 patients will be studied.

Direct interview with patient and obtaining a detailed history.

Thorough clinical examination.

A pretested structural proforma will be used to collect relevant information.

\section{Results}

Sex

\section{Table - I}

\begin{tabular}{|l|c|c|}
\hline & Frequency & Percent \\
\hline Female & 47 & 31.3 \\
\hline Male & 103 & 68.7 \\
\hline Total & 150 & 100.0 \\
\hline
\end{tabular}

One fifty patient were recruited into the study during the period of study.

The mean age of the cases included in the study was $23.75 \pm 11.75$;

103 cases were males $(68.70 \%)$ and 47 were females $(31.3 \%)$

\section{Complaints *Frequencies}

Table - II

\begin{tabular}{|l|c|c|c|}
\hline & $\mathrm{N}$ & Percent & Percent of Cases \\
\hline Pain & 148 & $60.9 \%$ & $98.7 \%$ \\
\hline Fever & 74 & $30.5 \%$ & $49.3 \%$ \\
\hline Vomiting & 21 & $8.6 \%$ & $14.0 \%$ \\
\hline Total & 243 & $100.0 \%$ & $162.0 \%$ \\
\hline
\end{tabular}

On evaluation of the complaints of the patients on admission to the emergency unit:

$98.7 \%$ had abdominal pain,

$49.3 \%$ had fever, and

$14.0 \%$ had vomiting.

\section{Anorexia}

Table- III

\begin{tabular}{|l|c|c|}
\hline & Frequency & Percent \\
\hline No & 72 & 48.0 \\
\hline Yes & 78 & 52.0 \\
\hline Total & 150 & 100.0 \\
\hline
\end{tabular}

On evaluation around $52 \%$ of patients $(n=78)$ had anorexia

$48 \%$ of patients $(n=48)$ had no anorexia.

\section{Nausea}

Table - IV

\begin{tabular}{|l|c|c|}
\hline & Frequency & Percent \\
\hline No & 64 & 42.7 \\
\hline Yes & 86 & 57.3 \\
\hline Total & 150 & 100.0 \\
\hline
\end{tabular}

On evaluation $42.7 \%$ of patients $(n=64)$ had nausea

$57.3 \%$ of patients $(n=86)$ had no nausea.

\section{Tenderness}

Table - V

\begin{tabular}{|l|c|c|}
\hline & Frequency & Percent \\
\hline Yes & 150 & 100.0 \\
\hline
\end{tabular}

All patients presented to casualty with the complaints of pain abdomen, those who are included in the study had right iliac fossa tenderness $(n=150)$ 


\section{Rebound Tenderness}

Table - VI

\begin{tabular}{|l|c|c|}
\hline & Frequency & Percent \\
\hline No & 13 & 8.7 \\
\hline Yes & 137 & 91.3 \\
\hline Total & 150 & 100.0 \\
\hline
\end{tabular}

On evaluation $91.3 \%$ of patients $(n=137)$ had rebound tenderness and

$8.7 \%$ of patients $(n=13)$ had no rebound tenderness.

\section{Rise in Temperature}

Table - VII

\begin{tabular}{|l|c|c|}
\hline & Frequency & Percent \\
\hline No & 33 & 22.0 \\
\hline Yes & 117 & 78.0 \\
\hline Total & 150 & 100.0 \\
\hline
\end{tabular}

On evaluation $78.0 \%$ patients $(n=117)$ had rise in temperature and

$22.0 \%$ patients $(n=33)$ had no rise in temperature.

\section{Leucocytosis}

Table - VIII

\begin{tabular}{|l|c|c|}
\hline & Frequency & Percent \\
\hline Yes & 119 & 79.3 \\
\hline No & 31 & 20.7 \\
\hline Total & 150 & 100.0 \\
\hline
\end{tabular}

In our study we took WBC count more than 10,000 cells/mcl was taken as leucocytosis.

In 150 cases, the white blood cell count was high in 119 cases $(79.3 \%)$, and the white blood cell count was normal in 31 cases $(20.7 \%)$.

\section{Mas}

Table - IX

\begin{tabular}{|l|c|c|}
\hline & Frequency & Percent \\
\hline$<7$ & 46 & 30.7 \\
\hline$\geq 7$ & 104 & 69.3 \\
\hline Total & 150 & 100.0 \\
\hline
\end{tabular}

\section{Ultrasonography}

\section{Table - X}

\begin{tabular}{|l|c|c|}
\hline & Frequency & Percent \\
\hline Normal Appendix & 44 & 29.3 \\
\hline Acute Appendicitis & 106 & 70.7 \\
\hline Total & 150 & 100.0 \\
\hline
\end{tabular}

In our study all 150 patients underwent USG abdomen ,

in those USG showed acute appendicitis in 106 patients ( $70.7 \%$ ), and normal study in 44 patients $(29.3 \%)$.

\section{Histopathology}

Table - XI

\begin{tabular}{|l|c|c|}
\hline & Frequency & Percent \\
\hline Normal Appendix & 19 & 12.7 \\
\hline Appendicitis & 131 & 87.3 \\
\hline Total & 150 & 100.0 \\
\hline
\end{tabular}

In our study histopathology showed appendicitis in 131 patients $(87.3 \%$ ) and Normal appendix in 19 patients $(12.7 \%)$.

\section{Mas * Histopathology}

Table - XII

\begin{tabular}{|l|c|c|c|}
\hline \multirow{2}{*}{$<7$} & $\begin{array}{c}\text { Normal } \\
\text { Appendix }\end{array}$ & Appendicitis & Total \\
\cline { 2 - 4 } & 16 & 30 & 46 \\
\hline \multirow{2}{*}{$\geq 7$} & $34.8 \%$ & $65.2 \%$ & $30.7 \%$ \\
\cline { 2 - 4 } & $2.9 \%$ & 101 & 104 \\
\hline \multirow{2}{*}{ Total } & 19 & $97.1 \%$ & $69.3 \%$ \\
\cline { 2 - 4 } & $12.7 \%$ & $87.3 \%$ & 131 \\
\hline
\end{tabular}

Chi square $=29.335 \mathrm{df}=1 \quad \mathrm{P}$ value $=0.0001$

In 104 cases (69.3\%), the Alvarado score was found to be higher than 7 . This score was found to be less than 7 in 46 cases (30.7\%).

The sensitivity of the Alvarado score was calculated as $84.2 \%$, the specificity as $77.1 \%$.

\section{Ultrasonography * Histopathology:}

Table - XIII

\begin{tabular}{|l|c|c|c|}
\hline & Normal Appendix & Appendicitis & Total \\
\hline \multirow{2}{*}{$\begin{array}{l}\text { Normal } \\
\text { Appendix }\end{array}$} & 14 & 30 & 44 \\
\cline { 2 - 4 } & $31.8 \%$ & $68.2 \%$ & $29.3 \%$ \\
\hline \multirow{2}{*}{$\begin{array}{l}\text { Acute } \\
\text { Appendicitis }\end{array}$} & 5 & 101 & 106 \\
\cline { 2 - 4 } Total & $4.7 \%$ & $95.3 \%$ & $70.7 \%$ \\
\cline { 2 - 4 } & 19 & 131 & 150 \\
\hline
\end{tabular}

Chi square $=20.644 \mathrm{df}=1 \mathrm{P}$ value $=0.0001$

According to these results, in all the cases, the sensitivity of USG was determined as $73.7 \%$, specificity as $87.3 \%$. 
In our study, 60 cases (40\%) had undergone open appendicectomy and 90 cases (60\%) had undergone laparoscopic appendicectomy.

\section{Sex * Histopathology}

Table - XIV

\begin{tabular}{|l|c|c|c|}
\hline \multirow{3}{*}{ Female } & Normal Appendix & Appendicitis & Total \\
\cline { 2 - 4 } & 7 & 40 & 47 \\
\hline \multirow{2}{*}{ Male } & $4.68 \%$ & $26.65 \%$ & $31.3 \%$ \\
\cline { 2 - 4 } & 12 & 91 & 103 \\
\hline \multirow{2}{*}{ Total } & $8.02 \%$ & $60.64 \%$ & $68.7 \%$ \\
\cline { 2 - 4 } & 19 & 131 & 150 \\
\hline
\end{tabular}

Chi square $=0.307 \mathrm{df}=1 \mathrm{P}$ value $=0.58$

In our study histopathological examination showed normal appendix in 19 cases (12.7\%), Of which 7 were females $(4.68 \%)$ and 12 were males $(8.02 \%)$.

Histopathology examination showed Appendicitis in 131 cases $(87.3 \%)$, of which 40 were females $(26.65 \%)$ and 91 were males $(60.64 \%)$.

Table - XV

\begin{tabular}{|l|c|c|c|}
\hline \multirow{3}{*}{ Female } & Normal Appendix & Appendicitis & Total \\
\cline { 2 - 4 } & 7 & 40 & 47 \\
\hline \multirow{3}{*}{ Male } & $14.9 \%$ & $85.1 \%$ & $31.3 \%$ \\
\cline { 2 - 4 } & 12 & 91 & 103 \\
\hline \multirow{2}{*}{ Total } & $11.7 \%$ & $88.3 \%$ & $68.7 \%$ \\
\cline { 2 - 4 } & 19 & 131 & 150 \\
\hline
\end{tabular}

Chi square $=0.307 \mathrm{df}=1 \mathrm{P}$ value $=0.58$

According to histopathological study, in total number of males $11.70 \%$ showed normal appendix and $88.30 \%$ showed appendicitis.

According to histopathological study, in total number of females $14.90 \%$ showed normal appendix and $85.10 \%$ showed appendicitis.

\section{T-Test}

\section{Table - XVI}

\begin{tabular}{|c|c|c|c|c|c|}
\hline & Histopathology & $\mathrm{N}$ & Mean & $\begin{array}{c}\text { Std. } \\
\text { Deviation }\end{array}$ & \multirow{2}{*}{ P value } \\
\hline \multirow{2}{*}{ Age } & Normal Appendix & 19 & 24.63 & 9.221 & 0.752 \\
\cline { 2 - 5 } & Appendicitis & 131 & 23.75 & 11.615 & \\
\hline
\end{tabular}

Mean age of patients with normal appendix shown on histopathology is $25+/-9$ years

Mean age of patients with appendicitis shown on histopathology is $24+/$ - 11 years.

\section{Discussion}

- The diagnosis of acute appendicitis in patients presenting with typical clinical finding can be made mostly on the clinical and laboratory findings. Radiation of pain, loss of appetite, nausea, vomiting, and tenderness in the right lower quadrant, fever, and leukocytosis are highly effective and practical criteria for diagnosing acute appendicitis. However, about one third of the acute appendicitis cases have atypical clinical findings, symptoms, and laboratory findings. In these cases, radiological evaluations are required. ${ }^{5}$

- Acute appendicitis is primarily a disease of adolescents and adults and its peak incidence is in the 2 nd and 3 rd decades of life. ${ }^{6}$

$>$ In the study conducted by Demircan, et al., with 85 patients, the mean age was $33.5 \pm$ 12.8 years. $55.3 \%$ (47) of the patients were males and $44.7 \%$ (38) were females. $16.5 \%$ (14) of the patients were in the range of $17-20$ years of age $69.4 \%$ (59) were in the range of $20-50$ years of age, and $14.1 \%$ (12) were in the over 50years age group. ${ }^{7}$

$>$ In the study conducted by Dikicier, et al., $48 \%$ of the cases $(n=139)$ were males, 52 were (148) females and the mean age was $31 . .^{8}$

In our study, the patient age was in agreement with that of the literature, ${ }^{6,7,8}$ and as it is evaluated for gender, the male gender was higher.

- A careful patient history and detailed clinical examination are essential in the diagnosis of acute appendicitis. However, in the laboratory analyses, leukocytosis is a finding which supports the diagnosis of appendicitis. ${ }^{9}$

In the study conducted by Demircan, et al., with 85 patients, as $10,000 / \mathrm{mm} \geq$ was taken for the lower limit value for leukocytosis, only $4.7 \%$ of the patients $(n=$ 4) had values below this value. ${ }^{7}$ 
Our study, agreed with findings in literature as the white blood cell counts were high in and of the cohort.

- The most important initial symptom is pain, which is present in $90-100 \%$ of the patients. $^{10}$

- In a study carried out by Mentes, et al., in 22 cases $(27.5 \%)$, there was no pain radiation to the right lower quadrant and in $70 \%$ of cases, there was right lower quadrant tenderness, which was rebounding in $75 \%$ of cases, and the Rovsing's sign was positive $66 \%$ of the cases. $^{11}$

Consistent with the findings in this study. in our study, clinical examination findings consistent with the literature were present.

$>$ In a study carried out by Mentes, et al., in $63.7 \%$ of cases, the Alvarado score was higher than 7 : in $36.3 \%$ of the cases, the Alvarado score was determined as 6 and lower than $6 .^{11}$

In our study, the Alvarado score was 7 and above 7 in $61.3 \%$ of the cases.

$>$ In a study carried out by Chong, et al., regarding the Alvarado score, the sensitivity was determined as $68.3 \%$,the specificity as $87.9 \% .^{12}$

$>$ In another study carried out with a thousand patients, the sensitivity was determined as $87.41 \%$, the specificity as $74.39 \% .^{13}$

In our study, we calculated the sensitivity of the Alvarado score as $77.1 \%$, specificity as $84.21 \%$

$>$ Similar to our results, in the study conducted by Jalil, etal., the Alvarado score's sensitivity was reported as $66 \%$, specificity as $81 \%$, were reported. ${ }^{14}$

$>$ In another study conducted in 2004, the sensitivity of the Alvarado score was determined as 53.85 and the specificity was determined as $80 \%$.

Furthermore, it was reported that the sensitivity and specificity in males (56.4 and 100\%) were higher than those in females (48 and 62.5\%). ${ }^{15}$ The findings of our study were consistent with this study.

$>$ In other studies, it was reported that the sensitivity of Alvarado score in males were higher than that in females. 15,16

This study is consistent with the finding in the literature, the sensitivity rate of the Alvarado score were higher in males.

$>$ In one of the studies, it was reported that the sensitivity of USG in acute appendicitis has been reported as $81-88 \%$ and the specificity has been reported as $78-84 \% .{ }^{17}$

$>$ In another study conducted by Wilson, et $a l$., the, the sensitivity of USG as $76-96 \%$, and the specificity as $47-94 \% .^{18}$

$>$ Orr, et al., found the sensitivity of USG in acute appendicitis as $85 \%$ and the specificity as $92 \% .^{19}$

$>$ In the study of Reich, et al., the sensitivity of USG was determined as $68 \%,{ }^{20}$ andwhile our USG results were lower than the results of previous studies.

The reason for the lower sensitivity, specificity of the USG may be due to the different evaluations of the patients by different radiologists with different experiences.

- It is important to reach an early and accurate diagnosis before the complications occur.

- The objective is to reduce the rate of negative appendectomy without increasing the perforation rate.

- While early surgical interventions performed to prevent complications have resulted in negative laparotomies in 8$30 \%$ of the cases, interventions that are performed late in order to wait for the clinical picture to fully settle, lead to an increase in the rate of perforated appendicitis. $^{21}$

Consistent with the literature, in our study, negative appendicectomies were determined in $7.89 \%$ of the cases, comparitivley lesser rate of negative appendicectomies.

$>$ In the study of Reich, et al., $10 \%$ of the cases in whom the USG findings were 
found to be compatible with appendicitis, resulted in negative laparotomies. ${ }^{20}$

In the study conducted by Parks, et al., the negative appendicectomy rate was reported as 5\% for USG and $12.2 \%$ for physical examination.

In our study, as the negative appendicectomy rates were consistent with the literature for Alvarado scores $(2.88 \%)$, the rates were determined to be high for USG $(4.71 \%){ }^{22}$

The disadvantages of USG depend on the experience of sonologist, not being performed optimally due to some problems originating from the patient (excess intra-abdominal fat mass, excessive intestinal gas, etc.) or the inability to visualize the appendix. ${ }^{23}$

\section{Conclusion}

Ultrasonography and Modified Alvarado Score are both beneficial in diagnosis of acute appendicitis. Though Ultrasonography is operator dependent, it has reasonable sensitivity and specificity in diagnosis. Moreover; a cut-off point of 7 for the MASS score will yield more sensitivity and a better diagnosis of appendicitis, with lower incidence of negative appendectomy compared to the previous studies.

\section{References}

1. Jan H, Khan J. evaluation of modified alvarado score in the diagnosis of acute appendicitis. 2007;23(4):4-6.

2. Lone NA, Shah M, Wani KA, Peer GQ. Modified Alvarado Score in Diagnosis of Acute Appendicitis. Indian Journal for the Practising Doctor. Vol.3, No.2 (2006-06)

3. Nautiyal H, Ahmad S, Keshwaniand NK, Awasthi DN. Combined use of modified Alvarado score and USG in decreasing negative appendicectomy rate. Indian Journal of Surgery, Feb. 2010; Volume 72, Number 1, pp: 46-52.

4. Al Qahtani HH, Muhammad AA. Alvarado score as an admission criterion for suspected appendicitis in adults. Saudi
J Gastroenterol 2004; 10: 86-91.

5. Lane MJ. Unenhanced helical CT for suspected acute appendicitis. Am J Roentgenol 1997;168:4059.

6. Addiss DG, Shaffer N, Fowler BS, Tauxe RV. The epidemiology of appendicitis and appendectomy in the United States. Am J Epidemiol 1990;132:91025.

7. Demircan A, Aygencel G, Karamercan M, Ergin M, Yilmaz TU, Karamercan A. Ultrasonographic findings and evaluation of white blood cell counts in patients undergoing laparotomy with the diagnosis of acute appendicitis. Ulus Travma Acil Cerrahi Derg 2010;16:24852.

8. Dikicier E, Altintoprak F, Cakmak G, Degirmenci B, Akbulut G. The use of ultrasound imaging for acute appendicitis. Sakarya Med J 2011;2:646.

9. Zielke A, Sitter H, Rampp T, Bohrer T, Rothmund M. Clinical decisionmaking, ultrasonography, and scores for evaluation of suspected acute appendicitis. World J Surg 2001;25:57884.

10. Yamaner S. Diseases of the appendix. In: Degerli U, Bozfakioglu Y, editors. Surgical Gastroenterology 5. Edition Istanbul: Nobel Medikal Bookstore; 2000. p. 16876.

11. Mentes O, Eryilmaz M, Yigit T, Tasci S, Balkan M, Kozak O, et al. Retrospectively analysis of appendectomies which performed elderly cases. J Acad Emerg Med 2008;4:3641.

12. Chong CF, Thien A, Mackie AJ, Tin AS, Tripathi S, Ahmad MA, et al. Comparison of RIPASA and Alvarado scores for the diagnosis acute appendicitis. Singapore Med J 2011;52:3405.

13. Limpawattanasiri C. Alvarado scora for the acute appendicitis in a provincial hospital. J Med Assoc Thai 2011;94:4419. [PUBMED]

14. Jalil A, Shah SA, Saaig M, Zubair M, Riaz U, Habib Y. Alvarado scoring system 
15. Al Hashemy AM, Selem MI. Apprasial of the modified Alvarado score for acute appendicits in adults. Saudi Med J 2004;25:122931.

16. Shrivastava UK, Gupta A, Sharma D. Evaluation of the Alvarado score in the diagnosis of acute appendicitis. Trop Gastroenterol 2004;25:1846.

17. Terasawa T, Blackmore CC, Bent S, Kohlwes RJ. Systematic review: Computed tomography and ultrasonography to detect acute appendicitis in adults and adolescents. Ann Intern Med 2004;141:53746.

18. Wilson EB, Cole JC, Nipper ML, Cooney DR, Smith RW. Computed tomography and ultrasonography in the diagnosis of appendicitis when are they indicated ? Arch Surg 2001;136:6705.

19. Orr RK, Porter D, Hartman D. Ultrasonography to evaluate adults for appendicitis: Decision making based on metaanalysis and probabilistic reasoning. Acad Emerg Med 1995;2:64450.

20. Reich B, Zalut T, Weiner SG. An international evaluation of ultrasound vs. computed tomography in the diagnosis of appendicitis. Int J Emerg Med 2011;29:68.

21. Yildirim E, Karagulle E, Kirbas I, Turk E, Hasdogan B, Teksam M, et al. Alvarado scores and pain onset in relation to multislice CT findings in acute appendicitis. Diag Interv Radiol 2008;14:148.

22. Parks JS, Jeon JH, Lee JI, Lee JH, Park JK, Moon HJ. Accuracies of diagnostic methods for acute appendicitis. Am Surg 2013;79:1016.

23. Puylaert JB. Acute appendicitis: US evaluation using graded compression. Radiology 1996;158:35560. 